\title{
sciendo
}

DOI 10.2478/sbe-2019-0048

SBE no. 14(3) 2019

\section{THE ROLE OF GENDER AND EDUCATION ON DECISION-MAKING}

\author{
MOSTERT JACQUES \\ South African College of Applied Psychology (SACAP), South Africa
}

GULSEVEN OSMAN

Middle East Technical University, Turkey

\begin{abstract}
:
In this article we investigated the predominance of six unique dimensions of decisionmaking. We defined those dimensions as rationality, acuity, autonomy, openness, control, and emotion-neutrality. Our data is based on an online survey conducted on a global scale. From this survey, we received a total of 356 responses, of which 204 (57.3\%) are females, and 152 (42.70\%) are males. Of the respondents, 139 (39.04\%) work in the education sector as teachers, academicians, lab instructors, course assistants and the remainder in other occupations. Our results suggest that emotion-neutrality is positively associated with all the dimensions of decision-making except acuity. We found that emotion-neutrality plays a significant role in the decision-making processes. However, female respondents perceive themselves to be less emotion-neutral, a finding that is amplified in the education sector. Thus, female teachers are more likely to make emotional decisions.
\end{abstract}

Key words: Diversity; Gender; Decision Making; Emotion Neutrality; Quantitative Methods and Statistics;

\section{Introduction}

Decision-making is a phenomenon that tries to explain how and why individuals engage in actions that may conclude in deleterious outcomes (Scott \& Bruce, 1995). Within the education sector, decision-making is 'a way of life' (Lunenburg, 2018) that permeates all levels of the education organizations, from administrators, leadership teams and classroom teachers. Research has been conducted on the correlation between communications, positive relationships, and democratization of decision-making structures (Cranston, 2001). However, there is a dearth of understanding how emotion, as a dimension of decision-making, may impact the development of education policy and practices.

In the field of psychology, decision-making has received much attention 
(Kahneman \& Tversky, 2000). Current research either places emphasis of neurological investigation on the neuro-biological process of decision-making, or it explores the phenomenon of decision-making as a sequential process. Whereas, the field of neurobiology explores the individual brain areas that are involved in decision-making, a sequential understanding of decision-making considers alternative strategies, determines the possible consequences that may result from each alternative and allows for a comparative evaluation that may lead to successful outcomes of these sets of consequences (Simon, 1997).

Scott and Bruce (1995) considers decision-making as a process or style that is a 'learned, habitual response pattern exhibited by an individual when confronted with a decision situation'. They distinguished between five distinct styles: rational, intuitive, reliant, avoidant and spontaneous, which does not provide elucidation on the various dimensions of decision-making. Neither of the neuro-biological, sequential or decision-making style approaches has provided a deeper understanding of how individuals or groups have made decisions in the education sector. In this article we propose six dimensions of decisionmaking that may elucidate the decision-making process: rationality (Simon, 1997), acuity (Malewska, 2017), autonomy (Spicer \& Sadler-Smith, 2005), openness to experience (Connelly, Ones, \& Chernyshenko, 2014), locus of control (Petri \& Govern, 2013), and emotion-neutrality (Feldman-Barret, Lisa Niedenthal, Paula M. Winkielman, 2005). We measure these dimensions from data collected by means of an online survey from 356 respondents. Our results support that each dimension is a unique one and also there are significant gender-employment sector differences regarding the prevalence of emotionneutrality in decision-making.

\section{Literature on Role of Emotions in Decision Making}

Emotions reflect a combination of conscious and unconscious processes and behaviours including decision-making processes. Emotion is the 'internal feeling state' that encompasses feelings, emotions and moods that forms as a result of an experienced stimulus. Emotion can take an evaluative judgment of 'liking' or 'disliking' for some object, person or situation (Tripathi, 2015). Fear, could be argued, is the emotion that has a significant impact on the decision-making process, is hard-wired into the limbic system, specifically the amygdala, has a survival function and serves to protect us from risk, thus playing an empowering role in the decision-making process. Thus, we may assert that emotion is innate in the human organism and cannot, under normal circumstances, be divorced from everyday situations, including the decision-making process.

Following these authors, we propose that emotion as a dimension of decisionmaking, may be regarded as a spectrum that ranges from emotion-reliant to emotionneutral. Being emotion-neutral, under normal circumstances, does not imply being opposed to being aware of the emotional impact of a decision on one self or others, nor does it propose that being able to constrain ones affective state is more favoured than being affect reliant. On the other hand, emotion-reliant individuals are often influenced by experiencing strong emotions that either activate or deactivate behaviours (Petri \& Govern, 2013), which in turn impact on how they react to decision-making situations. The 
strengthening of judgments of the possibility of preferential outcomes has an emotional impact on us and 'this amplification may reflect on our affective responses to positive and negative outcomes' (Tversky \& Fox, 2000). Therefore, emotion-reliant individuals may seek a solution that feels right, above a solution that fits a specific set of guidelines, yet feels uncomfortable.

It is also worth stating that an individual's experience of emotions may become an impeding feature throughout the decision-making process, could have deleterious impact on the outcomes of decisions. We propose that emotions as a dimension of decisionmaking, may contribute to a deeper understanding of how individuals and groups make decisions (Petri \& Govern, 2013).

According to Ekman and Cordaro (2011) "Emotions are discrete, automatic responses to universally shared, culture-specific and individual-specific events." There is a common dilemma on how to define and measure the emotion (Scherer, 2005). One challenge is to distinguish between the emotion and feelings. The feelings are based on instant reactions to external stimulants whereas emotions refer to the general state of these reactions. Thus, if one defines feeling as a flow variable, emotions can be defined as a stock variable. Once this definition is clarified, another challenge is to quantify the emotion level. Measuring the emotions using physical tools is a significant challenge for researchers (Duffy, Lajoie, Pekrun, \& Lachapelle, 2018). Therefore, most studies rely on self-reporting measures of emotion (Pekrun \& Bühner, 2014).

Another line of research in emotion studies is how gender affects the emotions. There is an increasing research on the relationship between gender and leadership (Eagly \& Heilman, 2016). The null hypothesis tested is whether male and female decision-makers show the same emotional behaviour whereas the alternative hypothesis states that female decision-makers are more emotional. This has led to another discussion on whether there is a prejudice or stereotyping against women. Several studies state that there are emotional stereotypes that claim women are more emotional than their male counterparts (Barrett \& Bliss-Moreau, 2009; Barrett, Robin, Pietromonaco, \& Eyssell, 1998). According to Adams (Adams, 2016) negative stereotyping is one of the reasons why female workers are less represented in the management. The gender diversity of company boards do not seem to contribute to better financial performance (Carter, D'Souza, Simkins, \& Simpson, 2010). However, stereotyping of women may lead to under representation, biased evaluation of female leaders in the workplace (Bergeron, Block, \& Echtenkamp, 2006; Brescoll, 2016; Brody, 2010; Butler \& Geis, 1990; Fischbach, Lichtenthaler, \& Horstmann, 2015). Commonly known as glass ceiling, this stereotyping may hinder the career advancement of female workers (Cross \& Linehan, 2006; Eagly \& Sczesny, 2009; Fitzsimmons \& Callan, 2016; Heilman, 2012). Studies show that even in a field like medical science, being a female doctor can affect the perceived performance by the patients (Roter \& Hall, 2015; Roter, Hall, \& Aoki, 2002).

Some studies claim that the prejudice against women is also present in group based decision-making activities (Cottrell \& Neuberg, 2005). The relationship between gender-role composition of the group and the role entrapment in group decision-making is significant (Johnson \& Schulman, 1989). The role of gender in emotional differences may also be attributed to the local culture or even to the ethnicity of the research participants 
(Brody, 2000; Durik et al., 2006; Fischer, Rodriguez Mosquera, van Vianen, \& Manstead, 2004).

There are also studies which suggest that the gender differences in professional behaviour is a naturally occurring phenomena. The stereotypes are changing and the gender gap is closing as more women integrate into the economy (Duehr \& Bono, 2006; Eagly, Diekman, Johannesen-Schmidt, \& Koenig, 2004). The inclusive participation of female workers in the labour market might naturally lead to gender differentiated roles within the economy (Charles, 2011). For example, female business owners are more likely to promote family-oriented company policies (Adkins, Samaras, Gilfillan, \& Mcwee, 2013). Similarly, companies that support women in leadership positions are more likely to cultivate female-friendly policies (Tate \& Yang, 2015).

The role played by emotions in education sector is also controversial. According to self-determination theory, motivation is an essential success factor in education (Deci, Ryan, Vallerand, \& Pelletier, 1991). Thus, engaging in an emotional student-teacher relationship might reinforce positive learning environment. According to Hargreaves (2000) the emotional interaction is an important learning factor in elementary school systems. Crossing the gender boundaries in education is important (Liu \& Li, 2017). Frenzel et al. (2007) prove that the performance of girls in mathematics courses is not different than their male counterparts. On the contrary, a recent empirical research on emotional intelligence suggested that students with higher emotional intelligence performed better in assessments (Chew, Zain, \& Hassan, 2013). Gender does not affect the self-efficacy in secondary education students (Salavera, Usán, \& Jarie, 2017). However, on the other hand, empirical research by Halberstadt et al. (2018) finds that the recognition of emotions by preservice teachers might be biased according to race and gender.

This article explores the role emotions, as an integral dimension of decisionmaking, plays in the phenomenon of decision-making. We follow an empirical approach to see if the role played by emotions in decision-making changes according to gender or sector. Thus, we specifically test whether differences exist between the effects of emotion on decision-making within the education sector in comparison with other sectors. We also test for the differences gender has on emotion as a dimension of decision-making.

\section{Materials and Methods}

Our general model is based on the framework that there are six dimensions of decision-making. To test this model, we followed a quantitative approach. We designed a six item Likert survey that required from the participant to indicate if each statement was very much like me to not like me at all with the very much like me option indicating the one end of the dimension spectrum and not like me at all the contrasting side. Each of the six dimensions were included in the survey. The data was gathered through an online survey conducted across several geographically distinct regions, and different age groups.

Participants were guaranteed anonymity and the survey allowed for discontinuation at any point. No identifying information such as e-mail addresses or IP addresses were gathered and through the reporting of data, identification of any participant is not possible. In addition, the nature of the survey does not allow for any emotionally or 
psychologically adverse influences to be experienced.

The collected data was initially organized by using Excel 2013. Next, we used Minitab 17 software to create cross tabulation tables and correlation matrix between each decision making dimension. We also used Minitab 17 software to create interaction plots for emotion neutrality dimension to investigate gender and sector differences. The hypothesis tests regarding the differences in gender and employment sector are calculated using the hypothesis testing and ANOVA modules in Minitab 17.

The descriptive data analysis shows that the median age group is 36-45. This group also forms the mode of the data based on different ages. The age distribution follows a somewhat normal distribution. In terms of geographical distribution, Western Europe represents the highest group followed by Africa and Middle East each of which has 134, 97, and 49 respondents. We also have 39 respondents from North America and 37 respondents from Australasia. Table 1 suggests cross tabulation of respondents based on location and age.

Table 1: Cross tabulation of respondents based on location and age

\begin{tabular}{|c|c|c|c|c|c|c|c|}
\hline & $\mathbf{1 9 - 2 5}$ & $\mathbf{2 6 - 3 5}$ & $\mathbf{3 6 - 4 5}$ & $\mathbf{4 6 - 5 5}$ & $\mathbf{5 6 - 6 5}$ & $\mathbf{6 5 +}$ & All \\
\hline Australasia & 1 & 5 & 14 & 11 & 6 & 0 & 37 \\
\hline Middle-East & 3 & 18 & 14 & 10 & 4 & 0 & 49 \\
\hline North America & 0 & 12 & 10 & 11 & 5 & 1 & 39 \\
\hline Africa & 10 & 26 & 33 & 17 & 6 & 6 & 97 \\
\hline Western Europe & 26 & 18 & 32 & 37 & 17 & 4 & 134 \\
\hline All & 40 & 79 & 103 & 86 & 38 & 10 & 356 \\
\hline
\end{tabular}

In terms of gender, we observe a relatively representative data similar to Karwowski (2012). We received a total of 356 responses 204 (57.3\%) of whom are females, and $152(42.70 \%)$ are males. However, our data is highly diversified in terms of employment sector. 139 respondents (39.04\%) work in education sector as teachers, academicians, lab instructors, course assistants, etc. whereas the rest works in diversified fields of other sectors. Table 2 below gives a cross tabulation of respondents based on gender and occupation.

Table 2: Cross tabulation of respondents based on gender and occupation sector

\begin{tabular}{|c|c|c|c|}
\hline & \multicolumn{3}{|c|}{ Occupation Sector } \\
\hline \multirow{2}{*}{ Gender } & Education & Others & All \\
\hline \multirow{2}{*}{ Female } & 89 & 115 & 204 \\
& $(25 \%)$ & $(32.30 \%)$ & $(57.30 \%)$ \\
\hline \multirow{2}{*}{ Male } & 50 & 102 & 152 \\
& $(14.4 \%)$ & $(28.65 \%)$ & $(42.70 \%)$ \\
\hline \multirow{2}{*}{ All } & 139 & 217 & 356 \\
& $(39.04 \%)$ & $(60.96 \%)$ & $(100 \%)$ \\
\hline
\end{tabular}


Our model assumes that decision making process involves six unique dimensions of decision making which are Rationality, Acuity, Autonomy, Openness, Control, and Emotion-neutrality. To see whether any of these dimensions is redundant, we created the correlation matrix between these dimensions.

The correlation matrix in Table 3 suggests that each category is measuring a distinct decision-making dimension as all correlations are relatively weak. We do not observe any strong correlation (above 0.5 ) between each dimension. However, although the correlations between decision-making dimensions are not strong, some of the correlations are statistically significant. Therefore while suggesting that each dimension is unique, the correlation matrix below also suggests that decision-making dimensions show some sort of association with each other.

Table 3: Correlation between decision making dimensions

\begin{tabular}{|c|c|c|c|c|c|c|}
\hline & Rationality & Acuity & Autonomy & Openness & Control & $\begin{array}{c}\text { Emotion } \\
\text { Neutrality }\end{array}$ \\
\hline Rationality & 1 & 0.042 & $0.247^{*}$ & 0.086 & $0.311^{*}$ & $0.336^{*}$ \\
\hline Acuity & 0.042 & 1 & $0.306^{*}$ & 0.051 & $0.247^{*}$ & 0.090 \\
\hline Autonomy & $0.247^{*}$ & $0.306^{*}$ & 1 & 0.017 & $0.239^{*}$ & $0.202^{*}$ \\
\hline Openness & 0.086 & 0.051 & 0.017 & 1 & -0.18 & $0.196^{*}$ \\
\hline Control & $0.311^{*}$ & $0.247^{*}$ & $0.239^{*}$ & -0.018 & 1 & $0.151^{*}$ \\
\hline $\begin{array}{c}\text { Emotion } \\
\text { Neutrality }\end{array}$ & $0.336^{*}$ & 0.090 & $0.202^{*}$ & $0.196^{*}$ & $0.151^{*}$ & 1 \\
\hline
\end{tabular}

*Significant correlations at $95 \%$ level.

Rational behaviour is positively associated with decision autonomy, internal locus of control, and emotion-neutrality. Similarly, acuity (analytical behaviour) is positively associated with autonomy and internal locus of control. Autonomy is positively associated with rationality, acuity, control, and emotion-neutrality. Openness is not associated with any other dimension except emotion-neutrality. Self-control is positively associated with rationality, acuity, autonomy, and emotion-neutrality. Emotional-neutrality is positively associated with all dimensions except acuity.

\section{Results}

\subsection{Dimensional Differences between Education vs Other Sector Workers}

We hypothesize that dimensional differences may exist between education sector workers (teachers, university lecturers, lab instructors, teaching assistants) and other sector workers. The null hypothesis is that there are no differences between education sector workers and other sector workers in terms of rationality, acuity, autonomy, openness, internal locus of control, and emotion neutrality. We use the t-statistics and the associated p-values to determine the outcome of each test. Table 4 shows a cross comparison of differences in decision-making dimension scores based on occupational sector. 
Table 4: Hypothesis Tests Education Sector vs Other Sector Workers

\begin{tabular}{|c|c|c|c|c|c|c|}
\hline & $\begin{array}{c}\text { Education } \\
\text { Sector }\end{array}$ & $\begin{array}{c}\text { Other } \\
\text { Sectors }\end{array}$ & $\begin{array}{c}\text { Mean } \\
\text { Difference }\end{array}$ & T-value & P-value & $\begin{array}{c}\text { Sectoral } \\
\text { Difference }\end{array}$ \\
\hline Rationality & $\begin{array}{c}8.11 \\
(1.61)\end{array}$ & $\begin{array}{c}8.00 \\
(1.85)\end{array}$ & $\begin{array}{c}0.113 \\
(0.19)\end{array}$ & 0.61 & 0.545 & None \\
\hline Acuity & $\begin{array}{c}6.71 \\
(2.21)\end{array}$ & $\begin{array}{c}7.11 \\
(2.08)\end{array}$ & $\begin{array}{c}-0.394 \\
(0.23)\end{array}$ & -1.68 & 0.094 & None \\
\hline Autonomy & $\begin{array}{c}8.14 \\
(1.91)\end{array}$ & $\begin{array}{c}8.19 \\
(1.86)\end{array}$ & $\begin{array}{c}-0.045 \\
(0.2)\end{array}$ & -0.22 & 0.826 & None \\
\hline Openness & $\begin{array}{c}6.35 \\
(2.47)\end{array}$ & $\begin{array}{c}5.90 \\
(2.66)\end{array}$ & $\begin{array}{c}0.454 \\
(0.28)\end{array}$ & 1.64 & 0.102 & None \\
\hline Control & $\begin{array}{c}7.96 \\
(1.68)\end{array}$ & $\begin{array}{c}7.81 \\
(1.76)\end{array}$ & $\begin{array}{c}0.158 \\
(0.19)\end{array}$ & 0.85 & 0.4 & None \\
\hline Emotion & $\begin{array}{c}5.49 \\
(2.23)\end{array}$ & $\begin{array}{c}5.80 \\
(2.31)\end{array}$ & $\begin{array}{c}-0.313 \\
(0.25)\end{array}$ & -1.27 & 0.204 & None \\
\hline
\end{tabular}

The analysis of test results in Table 4 suggest that education sector employees are more rational, more open to ideas, and more pro-active than other sector workers. They scored less in acuity, autonomy, and emotion neutrality dimensions. However, none of those differences are statistically significant at $95 \%$ confidence level. The only decision making dimension that is close to being statistically significant is the acuity dimension (at $90 \%$ confidence level) where workers in education sector tend to be more intuitive than other sector workers.

\subsection{Female vs Male Respondents}

We also make comparison between females and males regarding their decision making dimensions. The null hypothesis is that there are no differences between female respondents and male respondents in terms of rationality, acuity, autonomy, openness, internal locus of control, and emotion neutrality. Here, we also use the t-statistics and the associated $p$-values to determine the outcome of each test.

Table 5: Hypothesis Tests Female vs Male

\begin{tabular}{|c|c|c|c|c|c|c|}
\hline & Female & Male & $\begin{array}{c}\text { Mean } \\
\text { Difference }\end{array}$ & T-value & P-value & $\begin{array}{c}\text { Gender } \\
\text { Bias }\end{array}$ \\
\hline Rationality & $\begin{array}{c}8.11 \\
(1.66)\end{array}$ & $\begin{array}{c}7.94 \\
(1.89)\end{array}$ & $\begin{array}{c}0.172 \\
(0.19)\end{array}$ & 0.89 & 0.372 & None \\
\hline Acuity & $\begin{array}{c}7.09 \\
(2.14)\end{array}$ & $\begin{array}{c}6.76 \\
(2.13)\end{array}$ & $\begin{array}{c}0.330 \\
(0.23)\end{array}$ & 1.44 & 0.150 & None \\
\hline Autonomy & $\begin{array}{c}8.23 \\
(1.87)\end{array}$ & $\begin{array}{c}8.09 \\
(1.90)\end{array}$ & $\begin{array}{c}0.138 \\
(0.2)\end{array}$ & 0.69 & 0.494 & None \\
\hline Openness & $\begin{array}{c}6.09 \\
(2.65)\end{array}$ & $\begin{array}{c}6.06 \\
(2.52)\end{array}$ & $\begin{array}{c}0.029 \\
(0.26)\end{array}$ & 0.11 & 0.916 & None \\
\hline Control & $\begin{array}{c}7.89 \\
(1.70)\end{array}$ & $\begin{array}{c}7.84 \\
(1.78)\end{array}$ & $\begin{array}{c}0.057 \\
(0.19)\end{array}$ & 0.30 & 0.762 & None \\
\hline Emotion & $\mathbf{5 . 4 6}$ & $\begin{array}{c}\mathbf{5 . 9 8} \\
(\mathbf{2 . 2 9})\end{array}$ & $\begin{array}{c}\mathbf{- 0 . 5 2 4} \\
\mathbf{( 0 . 2 4 )}\end{array}$ & $\mathbf{- 2 . 1 5}$ & $\mathbf{0 . 0 3 2}$ & Yes \\
\hline
\end{tabular}

The results in Table 5 suggest that women are slightly more rational, more analytical, more autonomous, more open, and more pro-active than men. However, the differences between men and women regarding these dimensions are not statistically significant. What is strikingly different is the emotion-neutrality dimension. Based on the 
data, we can be $95 \%$ confident that women are less emotion neutral compared to men. This result implies that women are significantly more affected from their emotions when making decision choices.

\subsection{Cross Comparison}

The test results suggested the need for a deeper analysis of differences between female and male participants regarding their emotion neutrality. Therefore, we tested the cross interaction affects between the gender and occupational sector regarding the emotion neutrality dimension. For this test, we use one-way ANOVA for identifying the interaction affects if they exist. The ANOVA model in Table 6 suggests 4 factor levels (Female-Education, Female-Others, Male-Education, Male-Others).

The default (null) hypothesis is as follows:

$\mathrm{H}_{0}$ : There is no difference in emotion-neutrality for each factor

The alternative hypothesis is defined as follows:

$\mathrm{H}_{\mathrm{a}}$ : At least one factor group has a different emotion-neutrality level

Table 6: One-way ANOVA: Emotion Neutrality vs Gender-Employment Sector

\begin{tabular}{|c|c|c|c|c|c|}
\hline Source & DF & SS & MS & F-Value & P-Value \\
\hline Gender-Sector & 3 & 34.14 & 11.379 & 2.21 & 0.086 \\
\hline Error & 352 & 1809.36 & 5.140 & & \\
\hline Total & 355 & 1843.50 & & & \\
\hline
\end{tabular}

At $95 \%$ confidence level, the data does not suggest any significant difference in emotion neutrality dimension. However, it suggests some significance at the $90 \%$ level which is investigated further in the next table. The mean emotion-neutrality scores across different gender-sector combinations are given in Table 7:

Table 7: Mean Emotion-Neutrality Scores

\begin{tabular}{|c|c|c|c|c|c|}
\hline Gender-Sector & $\mathbf{N}$ & Mean & Std. Dev & LCL & UCL \\
\hline Female-Education & $\mathbf{8 9}$ & $\mathbf{5 . 2 0}$ & $\mathbf{2 . 2 9}$ & $\mathbf{4 . 7 3}$ & $\mathbf{5 . 6 7}$ \\
\hline Female-Others & 115 & 5.65 & 2.22 & 5.24 & 6.07 \\
\hline Male-Education & $\mathbf{5 0}$ & $\mathbf{6}$ & $\mathbf{2 . 0 5}$ & $\mathbf{5 . 3 7}$ & $\mathbf{6 . 6 3}$ \\
\hline Male-Others & 102 & 5.97 & 2.40 & 5.53 & 6.41 \\
\hline
\end{tabular}

The data above suggests that regardless of the employed sector, male participants reported almost the same score on their emotion-neutrality. On the other hand, there is a difference in responses of female workers in education sector vs other sector female workers, which is significant at $90 \%$ level. This difference becomes more visible when we look at the interaction plot for emotion neutrality between gender and occupation-based decomposition of survey respondents. 
Figure 1: Cross Interaction Plot (Male vs Female and Education vs Other Sectors)

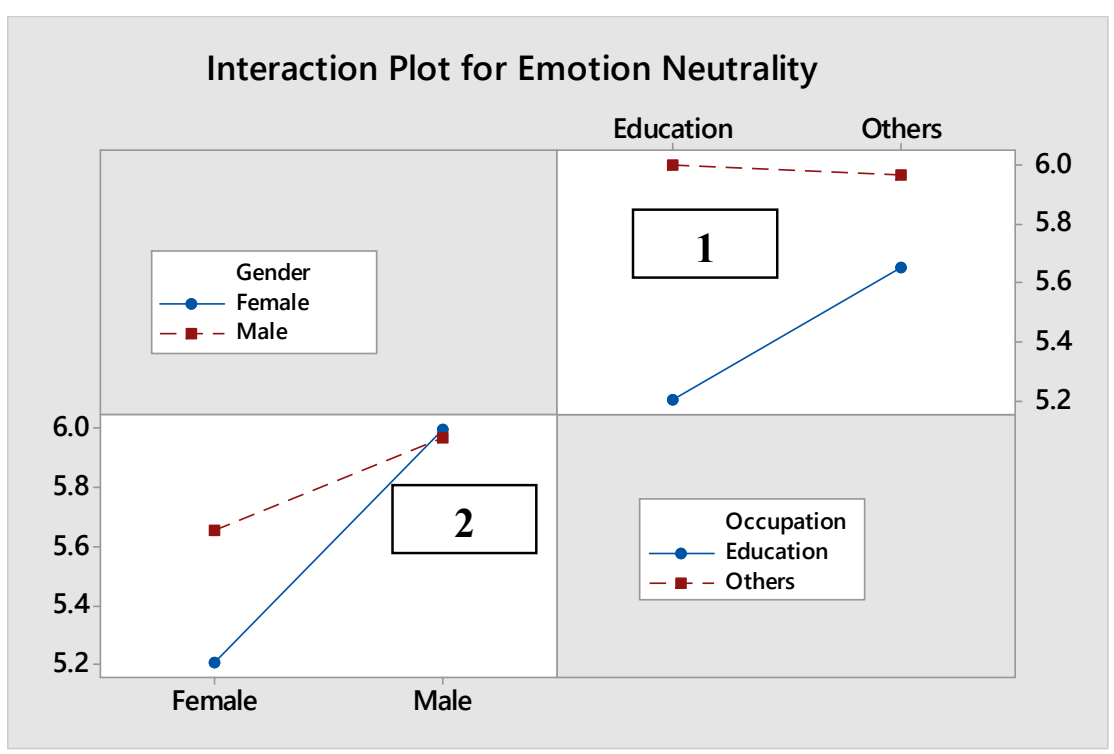

The first graph on the upper right corner of Figure 1 shows the differences between female and male respondents regarding emotion neutrality dimension. As can be seen in the interaction plot, regardless of the sector they work, females tend to be less emotion-neutral compared to males. This difference is magnified in the education sector where there is a difference of 0.8 points between female and male participants. Females working in education sector scored an average of 5.2 points, whereas males scored an average of 6 points out of 10 . The gap between female and male score is reduced to 0.32 points for those respondents working in other sectors. The mean emotion-neutrality score for male workers in other sectors is 5.97 , whereas for females in other sectors it is lower at 5.65 .

The second graph on the lower left corner of Figure 1 shows the differences education sector and other sector employees regarding emotion neutrality dimension. Male participants reported almost identical emotion neutrality scores of 6 and 5.97 regardless of the sector they are working in. This suggests that for males the working sector has no effect on emotion-neutrality. However, there is a distinctive difference between females working in the education sector and other sectors. Females working in other sectors scored 5.65 in emotion neutrality whereas females working in education sector reported only 5.2. Thus, female respondents working in education sector are significantly less emotion-neutral compared to all other groups in the analysis. This results implies that their decisions are more likely to be affected by their emotions.

\section{Discussion}

Our analysis of the survey data suggests that emotional-neutrality is positively associated with all dimensions of decision-making except acuity. The lack of association between acuity and emotion-neutrality may be explained in neurological terms. Acuity lies 
on a spectrum from purely analytical to mostly intuitive. Whilst analytical acuity may instinctively linked with emotional-neutrality we have to look at the originating point of human acuity, the unconscious mind. Kahneman and Tversky (2000) explains that thinking takes place on two plains of the mind: the conscious or knowing mind and the unconscious or unknowing mind. Acuity, be it analytical or intuitive, is primarily a function of the unconscious mind and though not mutually exclusive, it is not a direct function of emotion.

On the other hand, conscious emotion (awareness of emotive states and the ability to make decisions despite a state of affect) provide us with feedback on progress towards a goal, which lies at the heart of decision-making. In the same way, emotion also comes with an awareness of immediacy and urgency (Winkielman, Berridge, \& Sher, 2011), which contributes to the all-encompassing wholeness of the decision-making process. Thus, we put forward that including an awareness of emotion as a dimension of decision-making in the education sector enhances the quality of decisions made by teachers and leaders in education.

From the findings it is clear that emotion-dependence plays a significant role in the decision-making processes. Female respondents tend to perceive themselves to be less emotion-neutral in both the education and other sectors; a finding that is amplified in the education sector. For males there is no difference in emotion-neutrality during decisionmaking in the education or other sectors. Our findings are supportive of a study by Kelly and Hutson-Comeaux (2002) who suggest emotional expression in women.

At first sight, this finding could be seen as a dilemma for women who have been fighting a negative stereotype of emotional behaviour. However, the current investigation has not explored whether emotion as a dimension of decision-making is perceived in either a negative or positive way. Furthermore, the enquiry has not set out to investigate whether emotion-reliant decisions are indeed rational or irrational. Nor has it aimed to determine whether an individual's leaning towards being emotion-neutral or emotion-reliant, during the decision-making process, has any impact on the efficacy of the decisions made. On the contrary, we are in accord with the proposition that 'emotion is not antithetic to a rational decision process' (Gaudine \& Thorne, 2001), but rather an essential part of it. In addition, a circumflex model of emotion proposes that emotions, whether they are pleasant or unpleasant, can activate or deactivate behaviour (Yik, Russell, \& Steiger, 2011).

As suggested by Pulsford (2014), being emotional does not necessarily imply making irrational decisions. Barrett (Barrett, 2007) simulates an investing atmosphere to test the role of emotions in making successful investment decision. The author finds that those who feel more intense emotions achieved better decision-making performance. According to George (2000), the role played by emotional intelligence is highly significant in corporate culture.

In fact, given the social aspects of teacher-student relationship, being less emotion-neutral may lead to a more efficient learning process. As mentioned by Arreman and Weiner (2007), female teachers are more open to new education practices compared to their female counterparts. Thus, we need to emphasize that emotions should not be considered in terms of irrationality, but rather it can be a promoted aspect of the decisionmaking process.

There needs to be further investigation into the impact of emotion as a dimension 
of decision-making within all sectors. It would be advantageous to understand whether activating positive emotions contribute to the efficacy of the decision-making process or whether a complete state of emotional-neutrality is expedient in decision-making. As a phenomenon of the education sector, the impact of an emotion-reliant decision-making dimension has on the efficacy of education is worth to investigate further. More research is needed to figure out whether an emotion-neutral approach to day-to-day decisions in education is more beneficial to developing policy and practice as well as the teaching and learning of students. This, in turn, may enhance further development of pedagogical and leadership practices in the education sector.

\section{References:}

Adams, R. B. (2016). Women on boards: The superheroes of tomorrow? Leadership Quarterly, 27(3), 371-386. https://doi.org/10.1016/j.leaqua.2015.11.001

Adkins, C. L., Samaras, S. A., Gilfillan, S. W., \& Mcwee, W. E. (2013). The Relationship between Owner Characteristics, Company Size, and the Work-Family Culture and Policies of Women-Owned Businesses. Journal of Small Business Management, 51(2), 196-214. https://doi.org/10.1111/jsbm.12014

Arreman, I. E., \& Weiner, G. (2007). Gender, research and change in teacher education: A Swedish dimension. Gender and Education, 19(3), 317-337. https://doi.org/10.1080/09540250701295478

Barrett, L. F. (2007). Being Emotional During Decision Making -- Good or Bad? An Empirical Investigation. Academy of Management Journal, 50(4), 923-940. https://doi.org/10.5465/AMJ.2007.26279217

Barrett, L. F., \& Bliss-Moreau, E. (2009). She's emotional. He's having a bad day: attributional explanations for emotion stereotypes. Emotion, 9(5), 649-58. https://doi.org/10.1037/a0016821

Barrett, L. F., Robin, L., Pietromonaco, P. R., \& Eyssell, K. M. (1998). Are Women the "More Emotional" Sex? Evidence from Emotional Experiences in Social Context. Cognition and Emotion, 12(4), 555-578. https://doi.org/10.1080/026999398379565

Bergeron, D. M., Block, C. J., \& Echtenkamp, B. A. (2006). Disabling the able: Stereotype threat and women's work performance. Human Performance, 19(2), 133-158. https://doi.org/10.1207/s15327043hup1902_3

Brescoll, V. L. (2016). Leading with their hearts? How gender stereotypes of emotion lead to biased evaluations of female leaders. The Leadership Quarterly, 27(3), 415-428. Retrieved from https://www.sciencedirect.com/science/article/pii/S1048984316000151

Brody, L. R. (2000). The socialization of gender differences in emotional expression: Display rules, infant termperament, and differentiation. In A. H. Fischer (Ed.), Gender and emotion: Social psychological perspectives. (pp. 24-47). Cambridge: Cambridge University Press. https://doi.org/10.1017/CBO9780511628191.003

Brody, L. R. (2010). Gender and Emotion: Beyond Stereotypes. Journal of Social Issues, 53(2), 369393. https://doi.org/10.1111/j.1540-4560.1997.tb02448.x

Butler, D., \& Geis, F. L. (1990). Nonverbal Affect Responses to Male and Female Leaders: Implications for Leadership Evaluations. Journal of Personality and Social Psychology, 58(1), 48-59. https://doi.org/10.1037/0022-3514.58.1.48

Carter, D. A., D'Souza, F., Simkins, B. J., \& Simpson, W. G. (2010). The gender and ethnic diversity of US boards and board committees and firm financial performance. Corporate Governance: An International Review, 18(5), 396-414. https://doi.org/10.1111/j.1467-8683.2010.00809.x 
Charles, M. (2011). A World of Difference: International Trends in Women's Economic Status. SSRN (Vol. 37). https://doi.org/10.1146/annurev.soc.012809.102548

Chew, B. H., Zain, A. M., \& Hassan, F. (2013). Emotional intelligence and academic performance in first and final year medical students: A cross-sectional study. BMC Medical Education, 13(1), 44. https://doi.org/10.1186/1472-6920-13-44

Connelly, B. S., Ones, D. S., \& Chernyshenko, O. S. (2014). Introducing the Special Section on Openness to Experience: Review of openness taxonomies, measurement, and nomological net. Journal of Personality Assessment, 96(1), 1-16. https://doi.org/10.1080/00223891.2013.830620

Cottrell, C. A., \& Neuberg, S. L. (2005). Different emotional reactions to different groups: A sociofunctional threat-based approach to "prejudice." Journal of Personality and Social Psychology, 88(5), 770-789. https://doi.org/10.1037/0022-3514.88.5.770

Cranston, N. C. (2001). Collaborative decision-making and school-based management: Challenges, rhetoric and reality. Journal of Educational Enquiry.

Cross, C., \& Linehan, M. (2006). Barriers to advancing female careers in the high-tech sector: Empirical evidence from Ireland. Women in Management Review, 21(1), 28-39. https://doi.org/10.1108/09649420610643394

Deci, E. L., Ryan, R. M., Vallerand, R. J., \& Pelletier, L. G. (1991). Motivation and Education: The Self-Determination Perspective. Educational Psychologist, 26(3-4), 325-346. https://doi.org/10.1080/00461520.1991.9653137

Duehr, E. E., \& Bono, J. E. (2006). Men, women, and managers: Are stereotypes finally changing? Personnel Psychology, 59(4), 815-846. https://doi.org/10.1111/j.1744-6570.2006.00055.x

Duffy, M. C., Lajoie, S. P., Pekrun, R., \& Lachapelle, K. (2018). Emotions in medical education: Examining the validity of the Medical Emotion Scale (MES) across authentic medical learning environments. Learning and Instruction. https://doi.org/10.1016/J.LEARNINSTRUC.2018.07.001

Durik, A. M., Hyde, J. S., Marks, A. C., Roy, A. L., Anaya, D., \& Schultz, G. (2006). Ethnicity and gender stereotypes of emotion. Sex Roles, 54(7-8), 429-445. https://doi.org/10.1007/s11199-006-9020-4

Eagly, A. H., Diekman, A. B., Johannesen-Schmidt, M. C., \& Koenig, A. M. (2004). Gender Gaps in Sociopolitical Attitudes: A Social Psychological Analysis. Journal of Personality and Social Psychology, 87(6), 796-816. https://doi.org/10.1037/0022-3514.87.6.796

Eagly, A. H., \& Heilman, M. E. (2016, June 1). Gender and leadership: Introduction to the special issue. Leadership Quarterly, 27(3), 349-353. https://doi.org/10.1016/j.leaqua.2016.04.002

Eagly, A. H., \& Sczesny, S. (2009). Stereotypes about women, men, and leaders: Have times changed? In The glass ceiling in the 21st century: Understanding barriers to gender equality. (pp. 21-47). Washington: American Psychological Association. https://doi.org/10.1037/11863-002

Ekman, P., \& Cordaro, D. (2011). What is meant by calling emotions basic. Emotion Review, 3(4), 364-370. https://doi.org/10.1177/1754073911410740

Feldman-Barret, Lisa Niedenthal, Paula M. Winkielman, P. (2005). Emotion and Consiousness. New York: The Guilford Press.

Fischbach, A., Lichtenthaler, P. W., \& Horstmann, N. (2015). Leadership and gender stereotyping of emotions: Think manager - Think male? Journal of Personnel Psychology, 14(3), 153-162. https://doi.org/10.1027/1866-5888/a000136

Fischer, A. H., Rodriguez Mosquera, P. M., van Vianen, A. E. M., \& Manstead, A. S. R. (2004). Gender and Culture Differences in Emotion. Emotion, 4(1), 87-94. https://doi.org/10.1037/1528-3542.4.1.87

Fitzsimmons, T. W., \& Callan, V. J. (2016). Applying a capital perspective to explain continued 
gender inequality in the C-suite. Leadership Quarterly, 27(3), 354-370. https://doi.org/10.1016/j.leaqua.2015.11.003

Frenzel, A. C., Pekrun, R., \& Goetz, T. (2007). Girls and mathematics - A "hopeless" issue? A control-value approach to gender differences in emotions towards mathematics. European Journal of Psychology of Education, 22(4), 497-514. https://doi.org/10.1007/BF03173468

Gaudine, A., \& Thorne, L. (2001). Emotion and ethical decision-making in organizations. Journal of Business Ethics, 31(2), 175-187. https://doi.org/10.1023/A:1010711413444

George, J. M. (2000). Emotions and leadership: The role of emotional intelligence. Human Relations, 53(8), 1027-1055. https://doi.org/10.1177/0018726700538001

Halberstadt, A. G., Castro, V. L., Chu, Q., Lozada, F. T., \& Sims, C. M. (2018). Preservice teachers' racialized emotion recognition, anger bias, and hostility attributions. Contemporary Educational Psychology, 54, 125-138. https://doi.org/10.1016/J.CEDPSYCH.2018.06.004

Hargreaves, A. (2000). Mixed emotions: Teachers' perceptions of their interactions with students. Teaching and Teacher Education, 16(8), 811-826. https://doi.org/10.1016/S0742051X(00)00028-7

Heilman, M. E. (2012). Gender stereotypes and workplace bias. Research in Organizational Behavior, 32, 113-135. https://doi.org/10.1016/j.riob.2012.11.003

Hutson-Comeaux, S. L., \& Kelly, J. R. (2002). Gender stereotypes of emotional reactions: How we judge an emotion as valid. Sex Roles, 47(1-2), 1-10. https://doi.org/10.1023/A:1020657301981

Johnson, R. A., \& Schulman, G. I. (1989). Gender-role composition and role entrapment in decisionmaking groups. Gender \& Society, 3(3), 355-372. https://doi.org/10.1177/089124389003003005

Kahneman, D., \& Tversky, A. (2000). Choices, Values and Frames. Cambridge: Cambridge University Press.

Karwowski, M. (2012). Did Curiosity Kill the Cat? Relationship Between Trait Curiosity, Creative SelfEfficacy and Creative Personal Identity. Europe's Journal of Psychology, 8(4), 547-558. https://doi.org/10.5964/ejop.v8i4.513

Liu, H. Y., \& Li, Y. L. (2017). Crossing the gender boundaries: The gender experiences of male nursing students in initial nursing clinical practice in Taiwan. Nurse Education Today, 58, 72-77. https://doi.org/10.1016/j.nedt.2017.08.006

Lunenburg, F. C. (2018). National Policy/Standards. In The Wiley Handbook of Educational Supervision (pp. 379-405). Hoboken, NJ, USA: John Wiley \& Sons, Inc. https://doi.org/10.1002/9781119128304.ch16

Malewska, K. (2017). The profile of an intuitive decision maker and the use of intuition in decisionmaking practice. Management, 22(1), 31-44. https://doi.org/10.2478/manment-2018-0003

Pekrun, R., \& Bühner, M. (2014). Self-Report Measures of Academic Emotions. In Patricia A. Alexander, R. Pekrun, \& L. Linnenbrink-Garcia (Eds.), International Handbook of Emotions in Education. Routledge. https://doi.org/10.4324/9780203148211.ch28

Petri, H. L., \& Govern, J. M. (2013). Motivation: Theory, Research, and Application. Wadsworth, Cengage Learning.

Pulsford, M. (2014). Constructing men who teach: Research into care and gender as productive of the male primary teacher. Gender and Education, 26(3), 215-231. https://doi.org/10.1080/09540253.2014.901719

Roter, D. L., \& Hall, J. A. (2015). Women Doctors Don't Get the Credit They Deserve. Journal of General Internal Medicine, 30(3), 273-274. https://doi.org/10.1007/s11606-014-3081-9

Roter, D. L., Hall, J. A., \& Aoki, Y. (2002). Physician gender effects in medical communication: A meta-analytic review. Journal of the American Medical Association, 288(6), 756-764. https://doi.org/10.1001/jama.288.6.756 
Salavera, C., Usán, P., \& Jarie, L. (2017). Emotional intelligence and social skills on self-efficacy in Secondary Education students. Are there gender differences? Journal of Adolescence, 60, 39-46. https://doi.org/10.1016/J.ADOLESCENCE.2017.07.009

Scherer, K. R. (2005, December 29). What are emotions? and how can they be measured? Social Science Information. https://doi.org/10.1177/0539018405058216

Scott, S. G., \& Bruce, R. A. (1995). Decision-Making Style: The Development and Assessment of a New Measure. Educational and Psychological Measurement, 55(5), 818-831. https://doi.org/10.1177/0013164495055005017

Simon, H. A. (1997). Administrative Behavior: A Study of Decision-making Processes in Administrative Organization. New York: Free Press.

Spicer, D. P., \& Sadler-Smith, E. (2005). An examination of the general decision making style questionnaire in two UK samples. Journal of Managerial Psychology, 20(2), 137-149. https://doi.org/10.1108/02683940510579777

Tate, G., \& Yang, L. (2015). Female leadership and gender equity: Evidence from plant closure. Journal of Financial Economics, 117(1), 77-97. https://doi.org/10.1016/j.jineco.2014.01.004

Tripathi, M. N. (2015). Dissecting Affect: An Attempt to Understand its Influence on Consumer Decision Making. XIMB Journal of Management, 2(1), 98-114.

Tversky, A., \& Fox, C. R. (2000). Weighing Risk and Uncertainty. In Choices, Values, and Frames (pp. 93-117). Cambridge: Cambridge University Press.

Winkielman, P., Berridge, K., \& Sher, S. (2011). Emotion, Consciousness, and Social Behavior. The Oxford Handbook of Social Neuroscience. Oxford University Press. https://doi.org/10.1093/oxfordhb/9780195342161.013.0012

Yik, M., Russell, J. A., \& Steiger, J. H. (2011). A 12-Point Circumplex Structure of Core Affect. Emotion, 11(4), 705-731. https://doi.org/10.1037/a0023980 